\title{
Una vía decolonial para el pensamiento dicotómico en las concepciones de cultura
}

A decolonial way to dicotomic thought in the culture conceptions

ANA CECILIA CARRASCO QUINTANA*

Perú

*carrasco.cecilia@pucp.edu.pe

iD https://orcid.org/0000-0002-0958-1484

Artículo de investigación

Recepción: 16 de Octubre de 2019

Aprobación 26 de Febrero de 2020

Cómo citar este artículo:

Carrasco, A. (2019). Una vía decolonial para el pensamiento dicotómico en las concepciones de cultura. Designio. Investigación en diseño gráfico y estudios de la imagen 1(2),pp.17-39.

Recuperado a partir de: http://cipres.sanmateo.edu.co/index.php/designio 
Resumen: Este es un artículo de reflexión a partir del proyecto artístico-antipedagógico "Repite conmigo. Didácticas del olvido" (2016) de Ana Cecilia Carrasco; una exposición artística que aborda el pensamiento dicotómico como la subcategorización de componentes culturales indígenas. El proyecto artístico de referencia tuvo, entre otros elementos, una instalación de encuestas y testimonios recogidos en las ciudades de Puno, Trujillo y Chanchamayo, en Perú, en los que se evidencia indicios de "pensamiento dicotómico". Entre las dinámicas de mediación de este proyecto se destaca el "Taller de Crítica Gráfica", diseñado metodológicamente por la artista, junto a Miguel Det. Estas actividades tuvieron lugar en el Centro Cultural Bellas Artes (Lima, 2016). Este artículo analiza el proceso de construcción discursiva del proyecto y los resultados de sus dinámicas de interacción y mediación con el público, desde una postura decolonial, con el objetivo de ofrecer posibilidades de abordaje crítico del pensamiento dicotómico desde la mediación artística.

Palabras clave: pensamiento dicotómico; etnocidio simbólico; Perú; decolonialidad.

Abstract: This a reflection article since "Repeat after me. Didactics for forgetting" (2016) an artistic and antipedagogical proyect made by Ana Cecilia Carrasco. It is about dicotomic thought understood as the subcategory of ethnic cultural elements in Peru.

The project had, among other elements, an installation of surveys and testimonials from the cities of Puno, Trujillo and Chanchamayo, in Peru. These documents contain indications of dicotomic thought. Among the mediation dynamics of this Project, the "Graphic critic workshop" is relevant as a methodology designed by Ana Cecilia Carrasco y Miguel Det. All these activities were developed at the Cultural Center of Fine Arts in Lima, Peru. These article analyses the process of discursive construction oh the project and the results of its dynamics of interaction and mediation in relation to the public, from a decolonial position with the purpose of offering possibilities of critical approach to dicotomic thought from artistic mediation.

Keywords: Dicotomic thought; symbolic ethnocide; Peru; decoloniality. 


\section{Introducción}

La cultura como territorio simbólico es, potencialmente, un espacio de cohesión social donde se comparte códigos de convivencia. Cuando la pertenencia o no pertenencia a este espacio simbólico genera conflicto y dolor es, probablemente, cuando el pensamiento dicotómico actúa de por medio. Este territorio simbólico supone estar aprisionado a una condición de vida que no se ha elegido por propia voluntad, pero a la que se pertenece y donde, a la vez, no se puede permanecer.

Genera dolor ser ese otro oprimido y no el yo opresor en las dinámicas coloniales, donde el otro es inventado para diferenciar quiénes pertenecen a un proceso civilizatorio logrado. Estos nunca podrán obtener tal condición ni la solvencia cultural suficiente con la que reclamen cualquier aspecto de independencia por pertenecer a la barbarie; en sociedades conquistadoras y vencedoras "(...) El proceso de enfrentarse a la negatividad del otro es parte de un inevitable (y doloroso) proceso de construcción de un sí mismo positivo, virtuoso, deseable y racional" (Bustamante, 1999, p.137). Busca "radicalizar a la invención del otro, como contrapartida productiva de un modelo económico basado en la exclusión y el prestigio" (Figueroa, 2001, p. 182).

En consecuencia, el ser reivindicado, de forma sucesiva, consecutiva, y hasta natural, será siempre el yo. Entonces ¿quién es yo? Se torna en una pregunta más lógica y natural que ¿quién soy yo? La identidad, en estas circunstancias, no parte de un espejo, ni de uno mismo; parte de la legitimidad o no legitimidad exterior, en tanto ser o no ser el legitimado. Por qué el negro no es blanco, es más, el negro, tampoco puede ser negro; deberá ser rescatado de su condición por el blanco, o buscar no ser negro (Fanon, 2009). Sucede lo mismo en el caso del indio; su papel es el del vencido, el que debe ser integrado a la sociedad por el vencedor (Marzal, 1993).

En el Perú se pretende que tales alteridades no requieran problematización; todos somos mestizos y, por ello, iguales (Portocarrero, 2007). Sin embargo, cuando el concepto de cultura se ensombrece por la no cultura, y existe quien se siente amenazado y vulnerable por su condición de no ser el culto y ciudadano legítimo, es cuando aparece el pensamiento dicotómico; desvirtúa el supuesto principio de igualdad del que se viste el mestizaje. El pensamiento dicotómico superpone una sombra de fealdad frente a lo bello; una amenaza de salvajismo frente a lo civilizado; una necesidad de rescate frente a la barbarie.

El pensamiento dicotómico es un término propuesto en este texto para explicar el mecanismo de dominación; logra convencer al conquistado que su cultura es mala 
y que, después de una serie de aleccionamientos, él también -algún día- podrá ser parte de la buena cultura al erigirse sobre la base de dominio, extirpación, prohibición, y muertes simbólicas de la cultura. Este tipo de pensamiento distorsiona todo principio de justicia y libertad; acusa a los portadores de saberes y usos culturales no occidentales de ser una amenaza para el desarrollo y progreso del país. Un claro ejemplo de estas distancias humanas y sociales es el episodio del Baguazo en el año 2009 donde abiertamente Alan García, el entonces presidente, declaró respecto a los nativos amazónicos:

Estas personas no son ciudadanos de primera clase. Que puedan decir 400.000 nativos a 28 millones de peruanos 'tú no tienes derecho de venir por aquí.' De ninguna manera, eso es un error gravísimo y quien piensa de esa manera quiere llevarnos a la irracionalidad y al retroceso primitivo (La República, 2016).

Solo en un país que normaliza la exclusión, es posible que un presidente se atreva a lanzar declaraciones contra quienes forman parte del grupo humano al que debe su labor. Lo anterior, en una nación donde la mayoría es considerada un residuo de la sociedad, un componente externo que debe ser asimilado, un ser de menor condición que debe ser incorporado al proyecto de nación por formación o por la fuerza. El pensamiento dicotómico distorsiona; actúa como una extensión de las políticas de gobierno, pero ejercidas desde la propia conciencia: nuestra conciencia de ser un residuo del proyecto modernista.

Somos un caso de insalubridad debido al "carácter compulsivo del dominado se asemeja al comportamiento del fóbico" (Fanon, 2009, p. 70). Lo anterior por la concepción dual y contradictoria de un pasado mítico y un pasado épico que "cuajaron versiones de la historia que no respondían a las exigencias de una visión crítica (...) de modo que por un largo tiempo los problemas derivados del repentino encuentro fueron ignorados" (Hernández, 2000, p. 30).

Tanto Fanon como Hernández encuentran un desorden psicológico en la conciencia del dominado y del dominador derivado del colonialismo (Fanon, 2009) y la instalación de un antagonismo esencial (Hernández, 2000, p. 35) propio del encuentro entre dos culturas. Allí, una de ellas hace uso del poder y dominio sobre otra con estrategias tales como crear un campo simbólico a través del idioma, de forma que quien adquiera la lengua del dominado busque abandonar su con- 
dición cultural originaria (Fanon, 2009) o la de desvirtuar elementos de valor cultural y ritual, como el oro, y convertirlo en bienes mercantiles (Hernández, 2000).

Miguel Det explica el pensamiento dicotómico en el prólogo del "Pensamiento dicotómico ilustrado", un pequeño fanzine producido dentro del diseño de mediación en "Repite conmigo. Didácticas del olvido" como "la forma en que la atávica mentalidad colonial infiltra sus prejuicios, sentidos e idiologemas" (Carrasco, Det y Yáñez, 2016, p. 3). Es por su capacidad de ser cotidiano y sutil que el pensamiento dicotómico puede y debe ser abordado críticamente; especialmente en naciones que continúan replicando el colonialismo al colocar en situación vulnerable a sociedades que históricamente han sido desvirtuadas como referentes de cultura y conocimiento.

La estructura binaria del pensamiento dicotómico ha sido destacada en el proyecto artístico "Repite conmigo. Didáctica del olvido" para crear dinámicas de relación entre público y obra; utiliza pares dicotómicos a través de palabras, frases y símbolos gráficos. Los resultados de las interacciones llevan a corroborar la existencia de patrones de pensamiento que conciben al indígena, y a todo lo que él representa, como nocivo para el desarrollo. Patrones que reafirman nuestra condición de existir, como país, bajo la sombra de la eliminación.

A las luces del resultado del proyecto, como activador de discusiones y creaciones, se plantea su uso en la lectura de documentos textuales y gráficos, en especial, los que contienen ideales modernistas de las naciones. Surge la necesidad de entender el pensamiento dicotómico como política de gobierno enmascarada en paradigmas. Desde este artículo, se espera poder ofrecer algunas luces para ello.

\section{Etnocidio simbólico como didáctica del pensamiento dicotómico}

La fórmula educación = etnocidio simbólico resulta inmediata y efectiva para conectar las políticas de un país con el discurso de una sociedad regida bajo un cierta visión de país que trabaja por un desarrollo y modernización, gracias a la eliminación de elementos culturales indígenas.

Recordar y repetir. Recordar lo repetido. Repetir y reflexionar sobre lo repetido. Son algunas de las interacciones que el proyecto "Repite conmigo. Didácticas del olvido" intenta desarrollar para acceder al lugar de discusión desde el yo. Las prácticas etnocidas se conciben en este proyecto como encubrimientos y superposiciones utilizados en las construcciones discursivas de imágenes y oraciones, y en el uso de vocablos. Se conjetura que el significado de una palabra y el contenido conceptual de esta tiene dimensiones políticas, históricas e incluso pedagógicas. 
Frente a ello se hace necesaria la lectura crítica desde herramientas decoIoniales, que desarrollen la investigación y producción de saberes desde diversas disciplinas; desde las que incorporar formas de saber no occidentales y quiebren paradigmas. Se apuesta por decolonialidad en tanto muestra "primacía epistemológica, ética y política sobre la disciplina y el método" (Maldonado-Torres, 2016, p. 4). En ese sentido, en este artículo el estudio de la cultura encuentra la posibilidad de discutir con estructuras de pensamiento coloniales; usa formas de investigación transdisciplinares no tradicionales y valora las posibilidades relacionales del arte.

En el proyecto "Repite conmigo. Didácticas del olvido", uno de los efectos del rol relacional del arte es otorgar a la obra y al público un lugar íntimo de diálogo: La memoria personal. Por esto, el contenido etnocida de la imagen y de la palabra nos lleva no solo a deconstruir las estructuras de códigos comunicativos, también a recoger los insertos en nuestras memorias y expresados en nuestros modos de relación.

\section{Diálogos para la memoria en “Repite conmigo. Didácticas del olvido”}

El proyecto "Repite conmigo. Didácticas del olvido" fue diseñado para postular el ciclo de exposiciones "Memoria y ciudadanía" del Centro Cultural de Bellas Artes en la ciudad de Lima, Perú, en el año 2016. Este proyecto sustenta su propuesta en la formación de un archivo testimonial que corrobore la vigencia de enseñanzas escolares con contenido etnocida. El tipo de testimonio busca evidenciar el etnocidio simbólico como práctica cultural aprendida por peruanos de diversa procedencia, a través del sistema escolar.

En Chanchamayo, con la colaboración de la profesora Reneé Quintana, inicialmente se entrega una encuesta a sus estudiantes de segundo ciclo, de la carrera de derecho en la Universidad Peruana Los Andes; con las preguntas ¿Qué prácticas culturales cree que deben desaparecer en nuestro país? Y ¿Qué prácticas culturales deben permanecer en nuestro país? Entre la docena de estudiantes participantes de la encuesta, como respuesta prioritaria respondieron "la delincuencia y la corrupción"; respecto a la segunda "nuestras costumbres y folclore". Hasta entonces, no parece haber sustento que corrobore las suposiciones de una conciencia etnocida aprendida para descategorizar y desvirtuar el valor de nuestras costumbres y tradiciones indígenas.

Al preguntar ¿Ama a su país y sus costumbres? hay gran probabilidad que la respuesta sea SI. Sin embargo, si preguntamos las razones por las que se ama, cabe la posibilidad que las respuestas dejen entrever lecturas más complejas. En ese sentido lógico, se prosigue a rediseñar el cuestionario, de modo que las respuestas evidencien 
una conciencia dicotómica; al tiempo de dar valor al Perú, negar la posibilidad de ser valioso. Para ello se contacta a la docente del Colegio Fe y Alegría del Alto Trujillo, Rocío Carrasco para recoger audios testimoniales que respondieran a una guía de preguntas:

Tabla 1. Guía de preguntas para cuestionarios del proyecto "Repite conmigo. Didácticas del olvido".

\begin{tabular}{|l|}
\hline \multicolumn{1}{|c|}{ CUESTIONARIO } \\
\hline Nombre: \\
\hline $\begin{array}{l}\text { ¿Cuáles considera que son los aportes más importantes el Perú ha brindado al } \\
\text { mundo? }\end{array}$ \\
\hline $\begin{array}{l}\text { ¿Cuáles creen que han sido los aportes más importantes de Europa al Perú } \\
\text { desde la conquista española? }\end{array}$ \\
\hline $\begin{array}{l}\text { ¿Cuáles cambios creen que son los más importantes para que el Perú sea un país } \\
\text { ideal, que ofrezca un buen modelo de sociedad? }\end{array}$ \\
\hline $\begin{array}{l}\text { ¿Que manifestaciones culturales en el Perú considera que deben perdurar para } \\
\text { las generaciones venideras? (Danza, música, literatura etc) }\end{array}$ \\
\hline
\end{tabular}

Fuente: Carrasco, A., Det, M., y Yáñez, J., “El pensamiento dicotómico ilustrado”, 2016.

En la experiencia en Trujillo se recoge un conjunto de ocho (8) audios, con la participación de estudiantes y profesores. Estos audios, junto a otro tipo de testimonios pertenecientes a esta investigación, fueron parte de la exposición. Las preguntas “¿Cuáles considera que son los aportes más importantes que el Perú le ha brindado al mundo?" y ¿Cuáles cree que han sido los aportes más importantes de Europa al Perú desde la conquista española?", resultaron las más pertinentes para responder a los objetivos del proyecto. En ellos se refleja, por ejemplo, que la ciencia es reconocida como un aporte netamente Europeo. Por ello se optó por tabularlas; el resultado es ilustrado en la siguiente figura. Nótese que las barras azules corresponde a lo concebido como aporte Europeo y las barras amarillas como lo concerniente a los aportes del Perú al mundo. 
Figura 1. Tabulación de ocho encuestas respondidas en Trujillo.

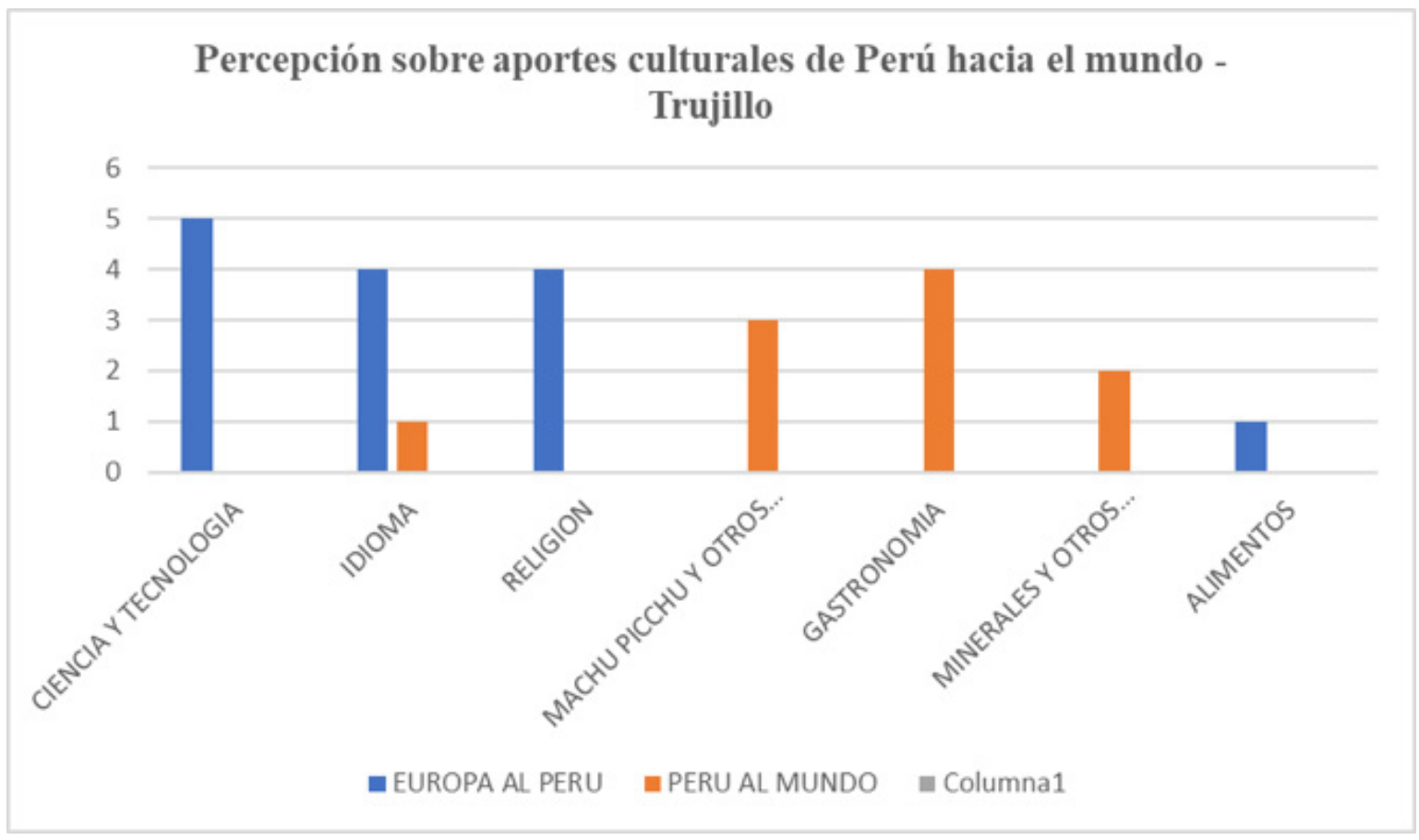

Fuente: Autoría propia (Lima, 2016).

Obtenidos los primeros resultados, se pone a prueba la guía de preguntas en un espacio geográfico y social diferente. En Puno, a través de la profesora Gilda Antezana, se aplica una encuesta escrita a niños de cuarto y quinto de secundaria del colegio San Juan de Huatta Huatta. A partir de los resultados se puede leer, de modo general, la percepción del Perú como fuente de riqueza (sea de tipo arqueológica, natural, o extractiva). Estas respuestas que señalan aportes científicos como la astronomía o la tecnología hidráulica, constituyen manifestaciones aisladas.

Por otro lado, Europa es valorada por su aporte en cultura, ciencia y tecnología, junto a los de tipo alimenticio. Cabe resaltar que en el Altiplano la crianza de animales y la siembra son actividades muy importantes; el ganado vacuno y la adaptación de granos y legumbres extranjeros es concebida como un aporte fundamental. En el público limeño, también existen muchas coincidencias entre estos tres (3) grupos anteriores; vincula Europa con la ciencia, la tecnología y la cultura y otorga a Perú la cualidad de ofrecer bienes y servicios. 
El patrón de preguntas y respuestas recogido de diferentes espacios socio culturales tiene similitudes, pero también diferencias. Cuando las respuestas tienen características muy particulares, se debe, generalmente, al contexto cotidiano y cultural. En la Universidad Sedes Sapientiae, en Atalaya, en el año 2017, fue socializada la dinámica de preguntas del proyecto, a modo de conversación abierta, con alumnos de la especialidad de Educación del sexto ciclo. Las similitudes con las respuestas reiterativas recogidas previamente fueron muy contundentes. Sin embargo, según lo expresaron más de tres (3) estudiantes, reconocieron un aporte importante de la Amazonía al mundo: la filosofía. Manifestaron que el pensamiento Amazónico es mucho más amplio que el occidental, lo cual no quita que los aportes de occidente sean importantes y necesarios.

Figura 2. Tabulación de 19 encuestas escritas en Puno.

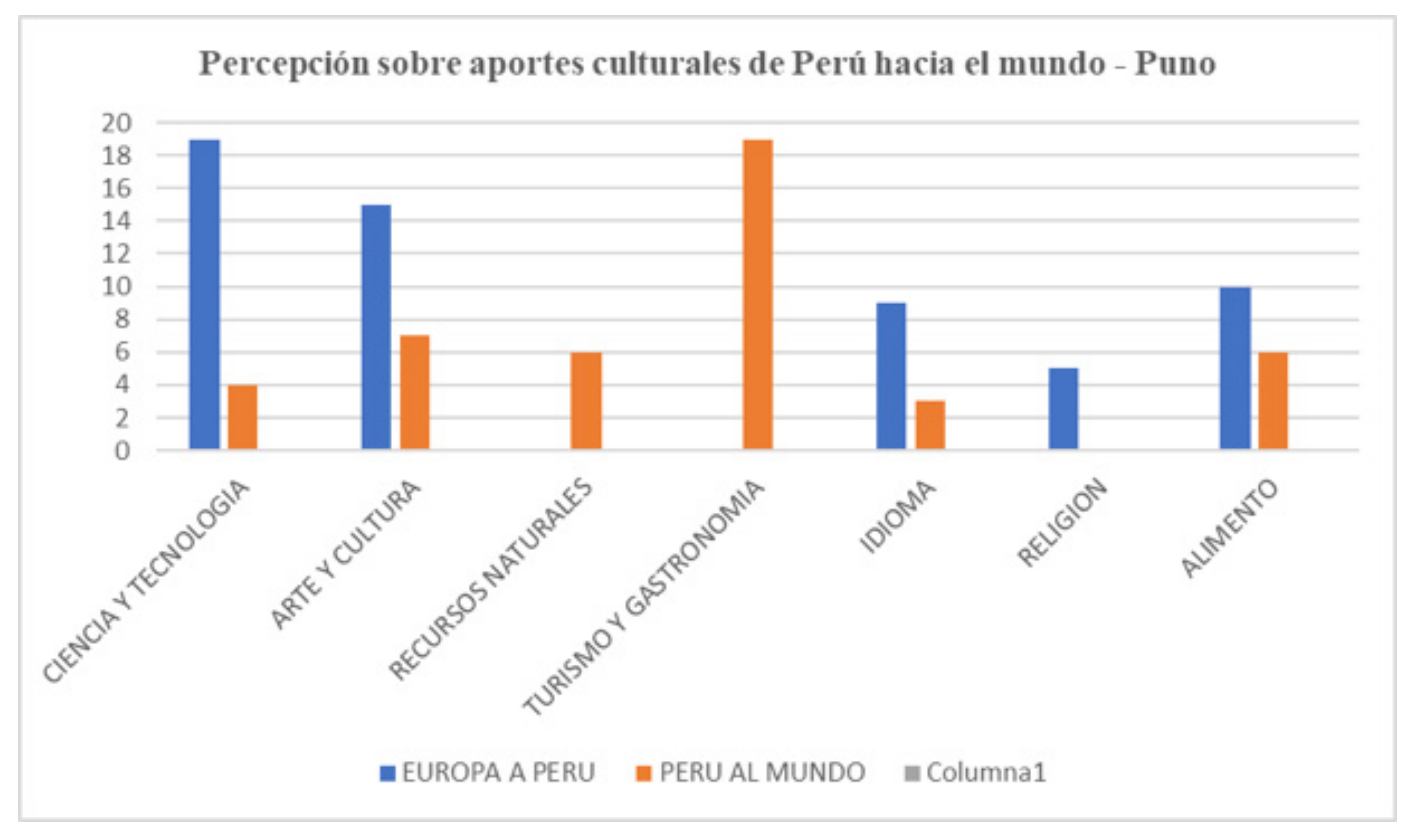

Fuente: Autoría propia (Lima, 2016).

Una particularidad de las encuestas respondidas en Lima, por el público asistente a "Repite conmigo. Didácticas del olvido", es agregar comentarios a sus respuestas. Si bien se podía corroborar, de modo general, percepciones similares entre limeños, puneños o trujillanos, los asistentes a la exposición en Lima estaban expuestos a información muy compleja, a la vez que dinámica, y tenían un panorama amplio para realizar observaciones sobre sus propias respuestas, o sobre las que leía alrededor. 
Figura 3. Grupo de 4 encuestas respondidas por estudiantes de colegio San Juan de Huatta Huatta".

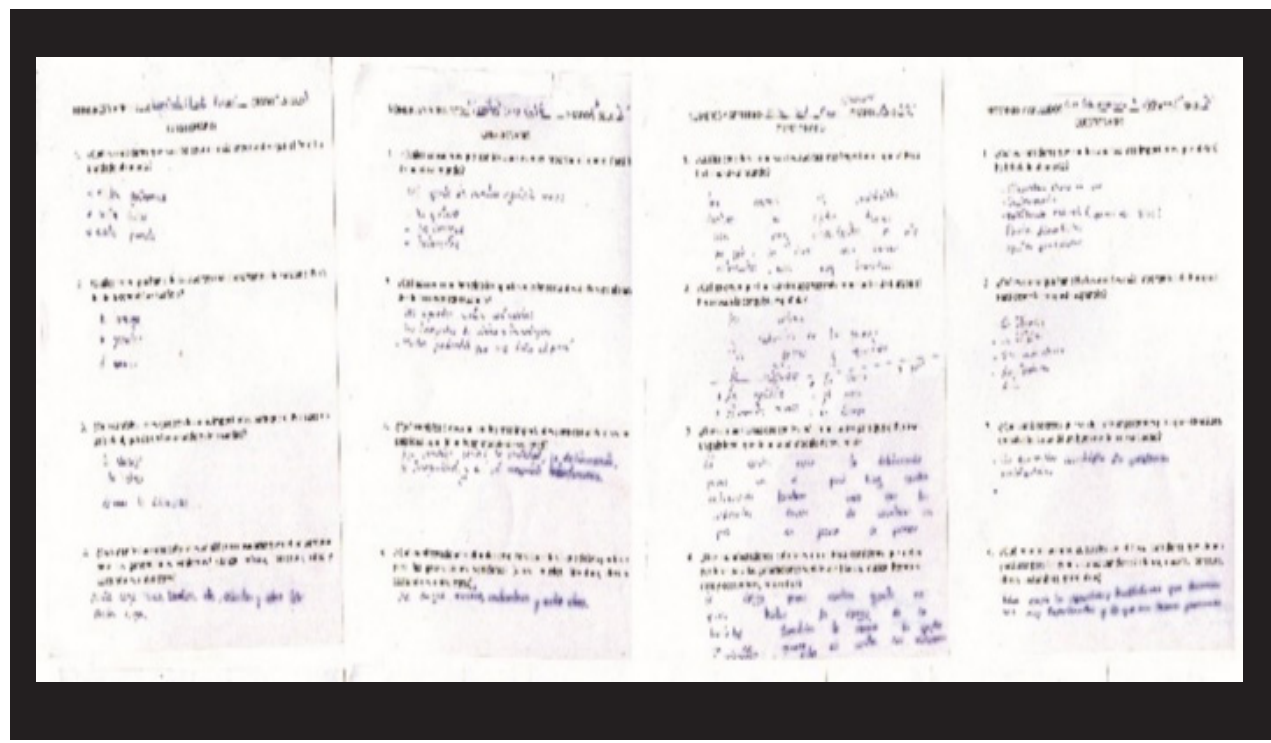

Fuente: Elaboración propia (Lima, 2016).

Figura 4. Tabulación de 20 encuestas respondidas durante la exposición "Repite conmigo. Didácticas del olvido".

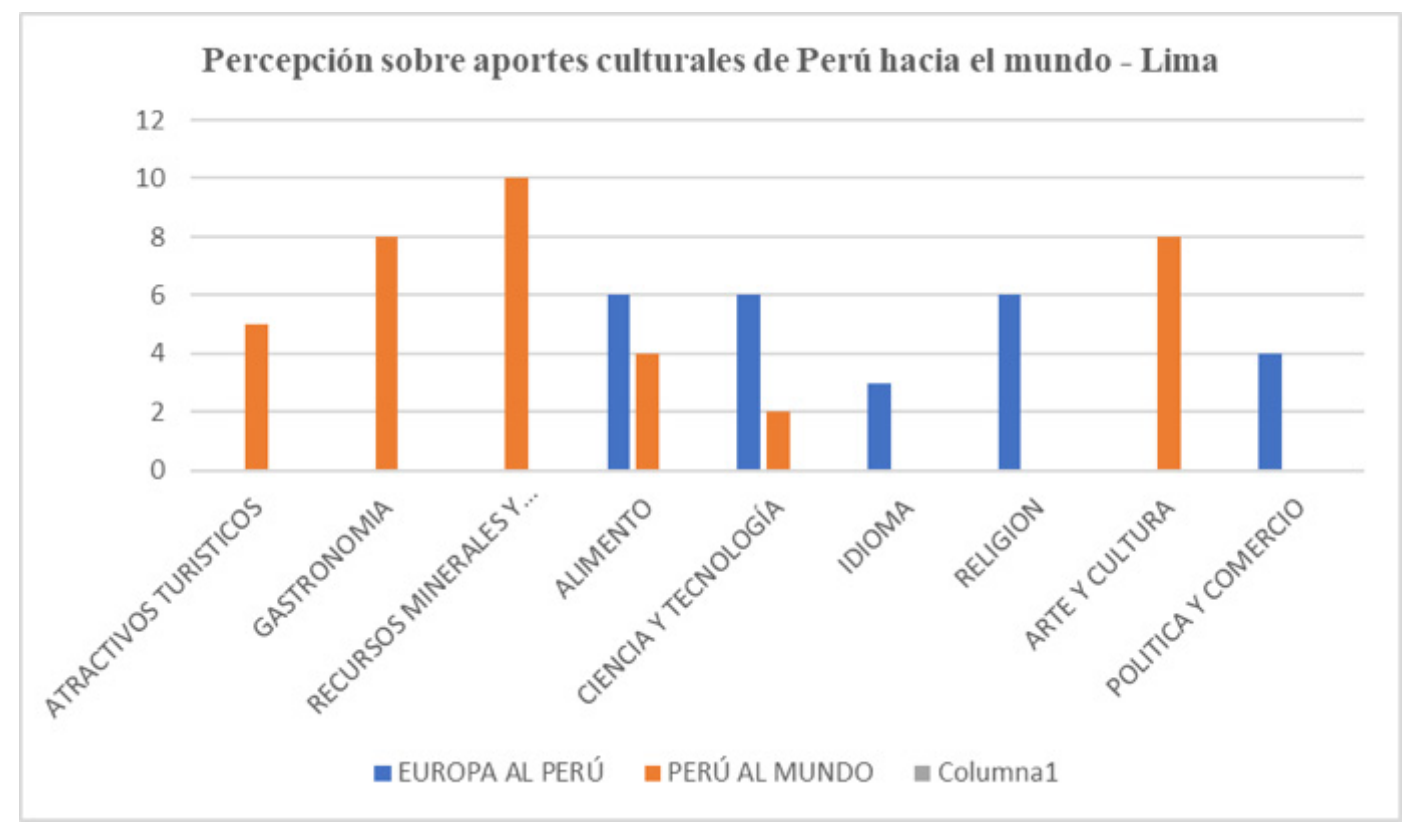

Fuente: Autoria propia (Lima, 2016). 


\section{Acercamiento a la dicotomía como aprendizaje}

El pensamiento dicotómico podría ser la doble conciencia criolla que denuncia Walter Mignolo, como procedente del proyecto modernista de la colonialidad (Lander, 2000). Es propulsora y auspiciadora de los proyectos pedagógicos para adiestrar nuestra percepción y conciencia de clase para que, cuando hablamos de civilizaciones, de costumbres cultas y de sabiduría, estemos hablando, a la vez, de incivilización, incultura y barbarie.

El concepto de hemisferio occidental ratifica la existencia del hombre occidental, al margen que viva o no en occidente (Lander, 2000, p. 95). El hemisferio es una línea imaginaria que separa y descategoriza todo lo no occidental. Sobre esa línea se yergue el pensamiento dicotómico, como la acción concreta que actúa desde una doble conciencia, aprendida a través de la educación. Reflexionar cómo ponemos en práctica estos aprendizajes, será la principal búsqueda de "Repite conmigo. Didácticas del olvido".

\section{El pensamiento dicotómico desde la representación}

La representación dicotómica del mundo indígena y del mundo occidental nos conduce a la valoración del intercambio; una nación inca generosa y diosas europeas agradecidas, semejantes a las fotos de viajeros en tierras turísticas. El mestizaje como ideal de nación ha sido una estrategia para contribuir a los procesos de asimilación y de incorporación, con el fin de contar con el sujeto dominado como mano de obra, como capital de producción (Quijano, 2014; Lander, 2000).

No obstante, tal asimilación y unidad europeo indígena no existe. Por ello, desde nuestra negación y orgullo por ser mestizo, estos dos componentes tenderán a dividirse. De modo que no debe extrañarnos nuestra familiaridad con los discursos etnocidas. Lo didáctica de la imagen ha sido para transmitir las distancias entre Europa y el indio, y lo bien que ejercemos tal aprendizaje.

\section{Estructura textual y visual del discurso dicotómico.}

Los siguientes textos son extractos de archivos investigados por Luis Glave (2013). Estos extractos de archivo, como parte de la exposición "Repite conmigo. Didácticas del olvido" explicitan el proyecto de las naciones coloniales. 
Figura 5. Guía didáctica Las buenas prácticas en exposición "Repite conmigo. Didácticas del olvido".

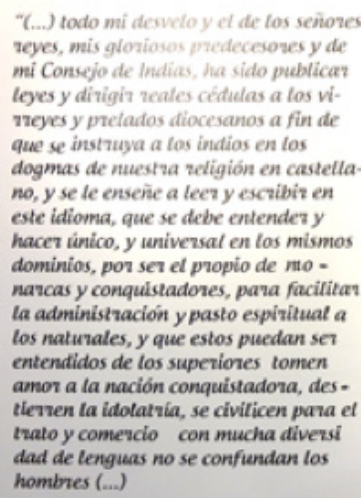

"(...) todo mi dewelo y el de tos serione zeyes, mis groziosas predecesones y de mi Consejo de Indias, ha sido publicar leyes $y$ dizigiz zeales cédulas a los $w^{\text {- }}$ vneyes y prelados diocesanos a fin de que se instruya a tes indios en tos dogmas de nuestana neligions en castetia.

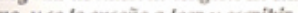
no, y se te ensence a lecry escribiz en este idioma, que se debe entender y hacer único, y universal en los mismos dominios, por ser el propio de mo narcas y conquistadones, para facilitas la administración y pasto espirituat a los naturales, $y$ que estos puedan sen entendidos de los superiones tomen amon a la de los supetiones tomen

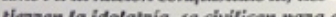
thernen ta idotatria, se trato y comercio con mucha diversi dad de lenguas no se confiendan los hombres (...)

"La verdadera educación india debe limitarse a dar instrucción cívica, lectura y escritura, aritméticay manejo de máquinas, abonos y animales..."

Diario La Razón La Paz 1942

... Ni estuviezan tan rudos tos indios ni tan extraños de nuestra politica y sociedad, si desde los principios de su conquista se hubiese olvidado su lengua, y sus costumbres, y naturalizados con la nuestza en aque. lla conformidad que suele introducir una lengua, una ley y unas costumbres y es la máxima fundamen tal de conservar las conquistas (...)"

Vizey Melchor de Navazza. Carta a Su Majestad. 1683

Fuente: Herbert Rodríguez, “Fotografías”, Lima, 2016.

La razón (1942) define el manejo de máquinas, abonos y animales como educación fundamental del indio (citado en Glave, 2013). También insiste en un idioma único para asegurar el dominio de las colonias en los virreinatos de Perú y México (Glave, 2013). No sólo es hermana de países, en su esencia colonial, además ha atravesado el tiempo; se transforma República y Colonia en un mismo espacio; sólo cambiaron las instituciones, no los paradigmas ni las necesidades de administración e incorporación de aquel elemento amenazante del proyecto modernista: el indio.

En el año 1942, la Brigada de educación indígena, realiza una cartilla escrita en tres (3) idiomas: castellano, quechua y aymara, en conmemoración al día del indio. Inicia recordándo que debe sentirse orgulloso por su "raza que ha hecho florecer (...) muchas civilizaciones" (Trapnell y Zavala, 2013, p. 113) En el cierre de la cartilla de buenas costumbres recalcan que está dormido, incompleto, y no desarrollado: "iDespierta, indio! Posees fortaleza, sólo te falta el saber. ¡Civilízate!" (Trapnell y Zavala, 2013, p. 116). Si pensamos en las voces en off que el indio puede figurar, al leer o escuchar el contenido de 
esta cartilla, no es posible que ocurra lo mismo en estas voces a sus ancestros. Quien salta a la conciencia, en el mundo de las representaciones, es el blanco: el patrón, el educador; el gobierno, que tiene a cargo a este hermanito menor que es el indio.

Ahora bien, tomando como referentes algunas representaciones ilustradas sobre el nuevo vínculo entre Perú y el mundo, se encuentra nuevamente el juego de alteridades entre lo glorioso europeo y lo glorioso incaico, para acoger desde Occidente a la nueva patria. La imagen parte de lo místico-indígena y épico-europeo en "La sabiduría y la elocuencia liberan del sepulcro al Inca Atahualpa".

La figura mítica y a la vez épica, ha sido derrotada y no tiene más nobleza que su sumisión. Sus símbolos de poder yacen sobre el suelo. El inca es rescatado compasivamente. La nación indígena observa a un indio pequeño e infantil. En la naciente república, el trauma del indio vencido (Hernández, 2000) será curado a través de la ciencia que Thot carga en sus manos.

Figura 6. Sara Paniagua. Fotografía de "L'sagesse avec l'eloquence trayte á Atahualpa du sepulcre" S. XIX, Quito, 2019. Pintura a óleo en el Museo Nacional de Historia del Ecuador.

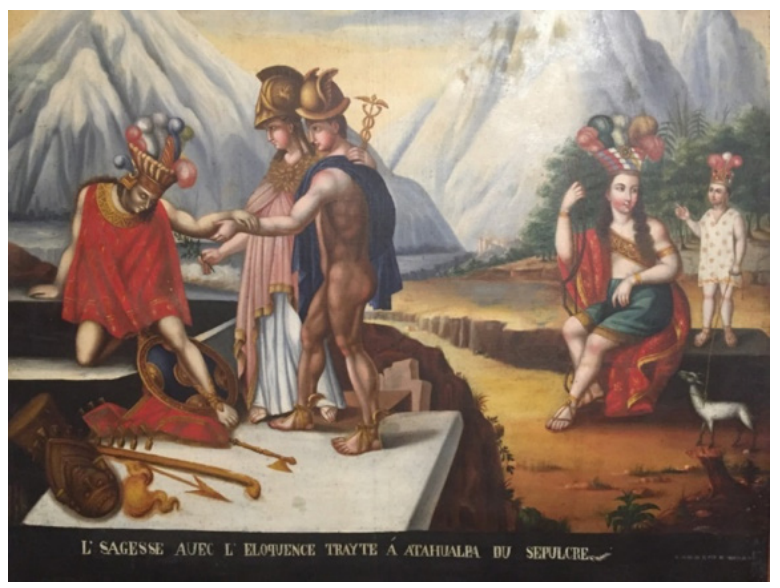

Fuente: Anónimo.

Una vez aclarado lo anterior, se revisan un par de publicaciones de distribución masiva y periódica que, a inicios de la República, refleja los ideales patrios. En ese sentido, se han seleccionado dos (2) imágenes. La primera es el encabezado que tuvo durante muchos años "El Perú llustrado"; diario dirigido por Peter Bacigalupi, migrante ítalo-norteamericano. Este semanario de las familias, producido y distribuido en Lima, entre 1887 y 1892, tiene carácter nacionalista; resalta la importancia de la tecnología y el desarrollo (Victorio, 2012). 
En el encabezado de "El Perú ilustrado" se observa la división meridional; Occidente ofrece el arte, la cultura y la explotación de riquezas. Tiene como fondo un socavón. Por su parte, no occidente ofrece naturaleza, animales, vasijas con representación antropo-zoomórficas y plantas. En medio, un indígena amazónico tensa una lanza contra el ferrocarril que viene del lado del occidentalismo y el progreso.

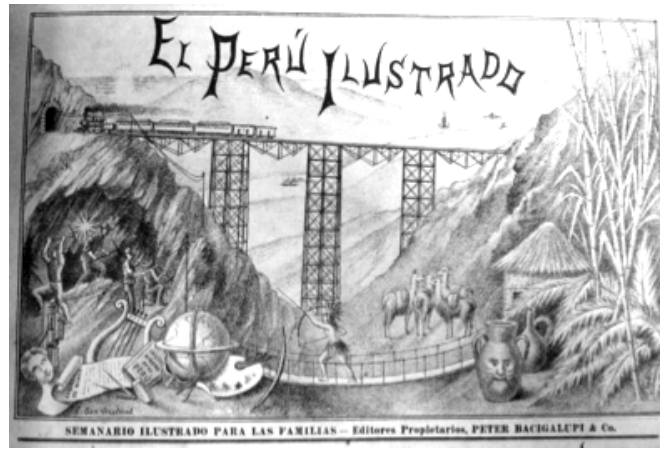

Figura 7. (Izquierda) Primera viñeta del Semanario Perú llustrado (1887 - 1892).

Fuente: Victorio, P., "La imagen en el Perú ilustrado", Lima, 2012.

Figura 8. (Derecha) Portada de El correo ilustrado del Perú.

Fuente: Vilca, E. (2009) "La imagen femenina: una visión contradictoria en el discurso del sujeto ilustrado en El Correo del Perú (1872)" en Velázquez, M. (2009, p.167) "La república de papel. Política e imaginación social en la prensa peruana del siglo XIX".

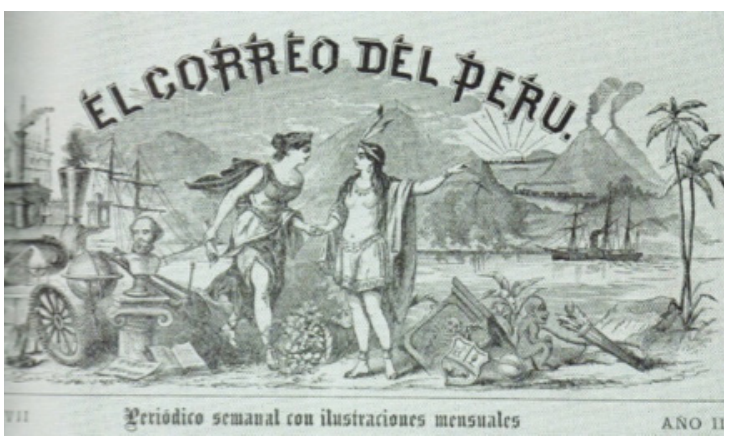

En la portada "El correo del Perú", la división meridional muestra menos antagonismo que en la imagen anterior. El comercio estrecha la mano de la patria. El comercio es una diosa griega mientras que la nación peruana viste atuendos incaicos. Ambas representaciones se debaten entre lo mítico y épico. El Perú se ha insertado, al fin, al comercio internacional, en pleno siglo XIX. El comercio ofrece las mejores riquezas de occidente: arte, rueda y escritura.

Las indias señalan al comercio un vasto territorio que requiere ser descubierto. La invitación a "descubrir" recuerda que aún nada ha sido encontrado, desarrollado, ni aprovechado. La cascarilla otorgó prosperidad comercial (Novoa, 2015) en una época en que los recursos naturales peruanos brindaron importantes aportes a la medicina. No obstante, el aporte siempre fue visto en relación al insumo y no al uso cultural que los pueblos andinos ancestralmente han desarrollado en torno a la medicina. 


\section{Interacciones del discurso dicotómico en "Repite conmigo. Didácticas del olvido"}

"Repite conmigo. Didácticas del olvido", utiliza un conjunto de binarismos con los que diseña tanto el proceso de investigación, como las piezas de instalación y las dinámicas de interacción y mediación. En secciones anteriores se ha expuesto parte del proceso de investigación. El siguiente paso es exponer algunas características de los elementos de instalación y comienza por un conjunto de pizarrones negros. Estos fueron elaborados, a su vez, considerando en ellos tres (3) divisiones: el encabezado, el cuerpo del pizarrón y, finalmente, el pie de objeto.

El encabezado recrea frases cliché, aprendidas en los cursos de ciencias sociales y humanidades en la etapa escolar. El cuerpo de las pizarras, rellenado a modo de plana caligráfica, intenta develar un concepto oculto que se desprende del enunciado. Por ejemplo, a partir de "La llegada de la fe verdadera", frase cliché aprendida en los cursos de religión, aprendemos a distinguir lo verdadero y falso. Evidentemente, lo propio y local siempre será falso y aquello ajeno verdadero. Los pies de objeto, colocados debajo de cada pizarra, daban a conocer el nombre de la materia impartida. Así, bajo la pizarra de "La llegada de la fe verdadera", según la exposición, se aprende el curso de "Cristiandad del etnocidio".

Figura 9. Pizarra, cuerpo y pie de objeto en detalle.
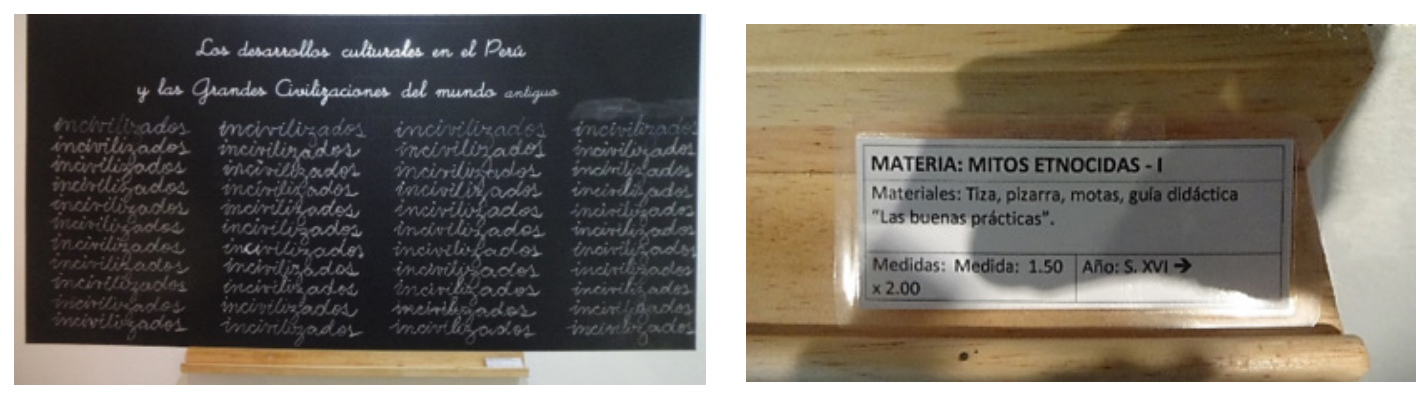

Fuente: Herbert Rodríguez Fotografías de la exposición

"Repite conmigo Didácticas del olvido", Lima, 2016. 
Tabla 2. Contenido de las pizarras instaladas en "Repite conmigo. Didácticas del Olvido".

\begin{tabular}{|c|l|l|l|}
\hline $\begin{array}{c}\text { Nro } \\
\text { Pizarra }\end{array}$ & \multicolumn{1}{|c|}{ Encabezados de pizarra } & \multicolumn{1}{|c|}{$\begin{array}{c}\text { Cuerpo de } \\
\text { pizarra }\end{array}$} & \multicolumn{1}{|c|}{ Pie de objeto } \\
\hline 1 & $\begin{array}{l}\text { "Las grandes civilizaciones del mundo } \\
\text { antiguo y los desarrollos culturales en el } \\
\text { Perú" }\end{array}$ & Incivilizados & $\begin{array}{l}\text { Materia: Historia y } \\
\text { sociedad }\end{array}$ \\
\hline 2 & "La llegada de la fe verdadera" & $\begin{array}{l}\text { Verdadero / } \\
\text { Falso }\end{array}$ & $\begin{array}{l}\text { Materia: Cristiandad del } \\
\text { etnocidio }\end{array}$ \\
\hline 3 & "El idioma único oficial" & Única Oficial & $\begin{array}{l}\text { Materia: Políticas } \\
\text { etnocidas }\end{array}$ \\
\hline 4 & "El glorioso pasado incaico" & Pasado & $\begin{array}{l}\text { Materia: Etnocidio cultural } \\
\text { I }\end{array}$ \\
\hline 5 & "Las artes son bellas. La artesanía popular" & No es arte & $\begin{array}{l}\text { Materia: Etnocidio cultural } \\
\text { II }\end{array}$ \\
\hline 6 & "La literatura es culta. La danza folclórica" & Incultos & $\begin{array}{l}\text { Materia: Etnocidio cultural } \\
\text { III }\end{array}$ \\
\hline
\end{tabular}

Fuente: Elaboración propia, Puno, 2016. 
Figura 10. Pizarras dicotómicas en "Repite conmigo. Didácticas del olvido".

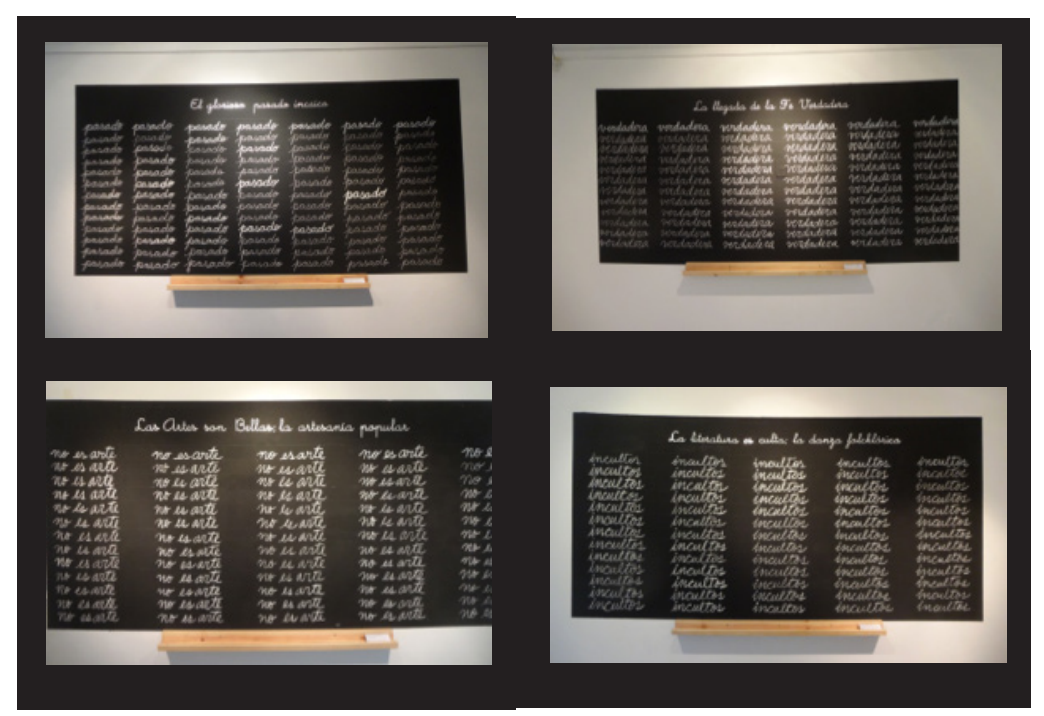

Fuente: Herbert Rodríguez. Fotografías de la exposición "Repite conmigo. Didácticas del olvido", Lima, 2016

¿Qué has aprendido a repetir? Fue una quinta pizarra intervenible a través de una nota adhesiva (o post-its) y bolígrafos. En las intervenciones digitalizadas, puede leerse la necesidad del público por responder a las provocaciones de la muestra desde exclamaciones de orgullo, alegría o ira, hasta reflexiones y confrontaciones. Lo anterior es ilustrado en la Figura 9, a continuación.

Figura 11. Interacciones en Repite conmigo. Didácticas del olvido.
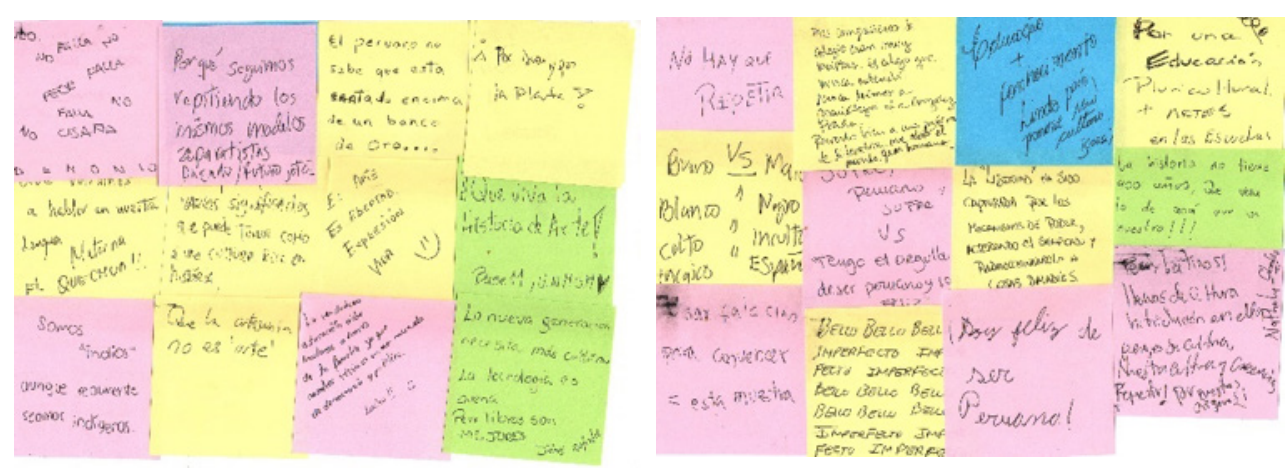

Fuente: Ana Cecilia Carrasco. “Digitalización de post its en Repite conmigo. Didácticas del Olvido", Lima, 2016. 
La siguiente imagen muestra parte de una sala lúdica de interacción en cuatro (4) pedestales provistos con cajas archivadoras e imágenes en tarjetas. Las cajas, a su vez, rotuladas bajo las categorías de culto e inculto. Las tarjetas representan usos y costumbres indígenas, criollas y europeas. El juego invita al público a separar lo culto de lo no culto.

Figura 12. Tarjetas de clasificación en "Repite conmigo. Didácticas del olvido".

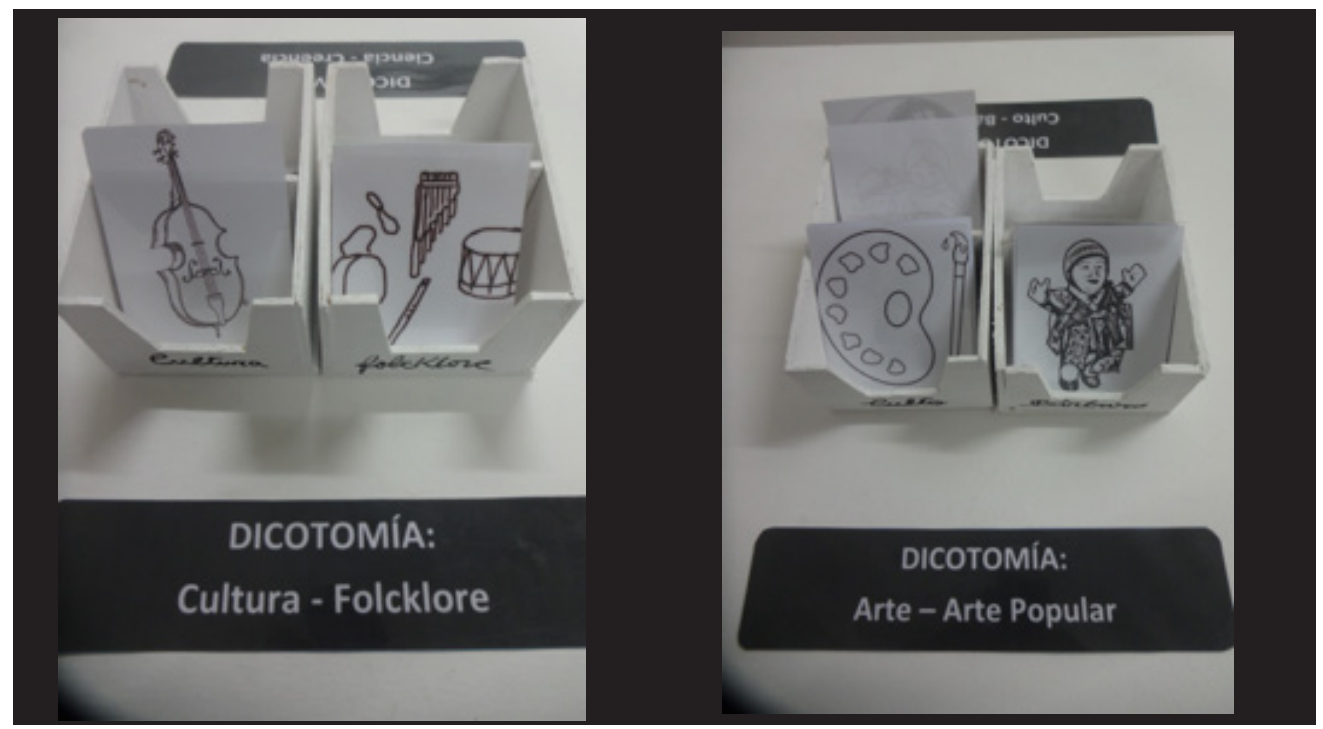

Fuente: Herbert Rodríguez. Fotografías de la exposición “Repite conmigo. Didácticas del olvido", Lima, 2016.

\section{Proyecto antipedagógico: Las quilcas guamanponianas ${ }^{1}$}

En diciembre del año 2016 se desarrolla el "Taller de crítica gráfica" como parte de las actividades de mediación de la muestra "Repite conmigo. Didácticas del olvido"; taller de producción de historietas colectivas, con la colaboración pedagógica de Miguel Det y Juan Carlos Yáñez. El taller fue una actividad de mediación que buscó implementar patrones gráficos no occidentales como estructura.

\footnotetext{
${ }^{1}$ Miguel Det es el seudónimo de Miguel Vidal. Miguel es un ilustrador peruano que en el año 2011 investigó la "Nueva crónica y buen gobierno", de Guamán Poma de Ayala. Como resultado de su investigación produjo su propia versión y actualización de estas crónicas narrativas a través de "Novísima crónica y mal gobierno" (Det, 2011) a través de la editorial Contracultura. Miguel Det utiliza el término "quilcas guamanponianas" durante el proyecto.
} 
Uno de los aportes más importantes de Miguel Det, al diseño y ejecución del taller, fue incorporar la estructura de la quilca guamanponiana en el lenguaje de la historieta; al ser capaz de englobar, en una sola imagen, diversos tiempos de acción a través de sus diferentes elementos: título, subtítulo, personajes en diferentes planos y dimensiones. La finalidad fue potenciar la contradicción como elemento narrativo a la hora de ofrecer como posibilidad estas dinámicas de superposición de planos y tiempos.

Como material de apoyo se diseñó un cuaderno de trabajo, dividido en referencias gráficas y áreas en blanco para dibujar. Como referencia gráfica se seleccionaron imágenes que respondieran a los pares dicotómicos: Cultura - folcklore / Culto - bárbaro / Religión - idolatría / Lengua - dialecto/ Arte - arte popular / Ciudadano - poblador / Medicina - curanderismo / Cocina peruana - plato típico.

Figura 13. Pares dicotómicos en Cuaderno de trabajo, para Taller de crítica gráfica.

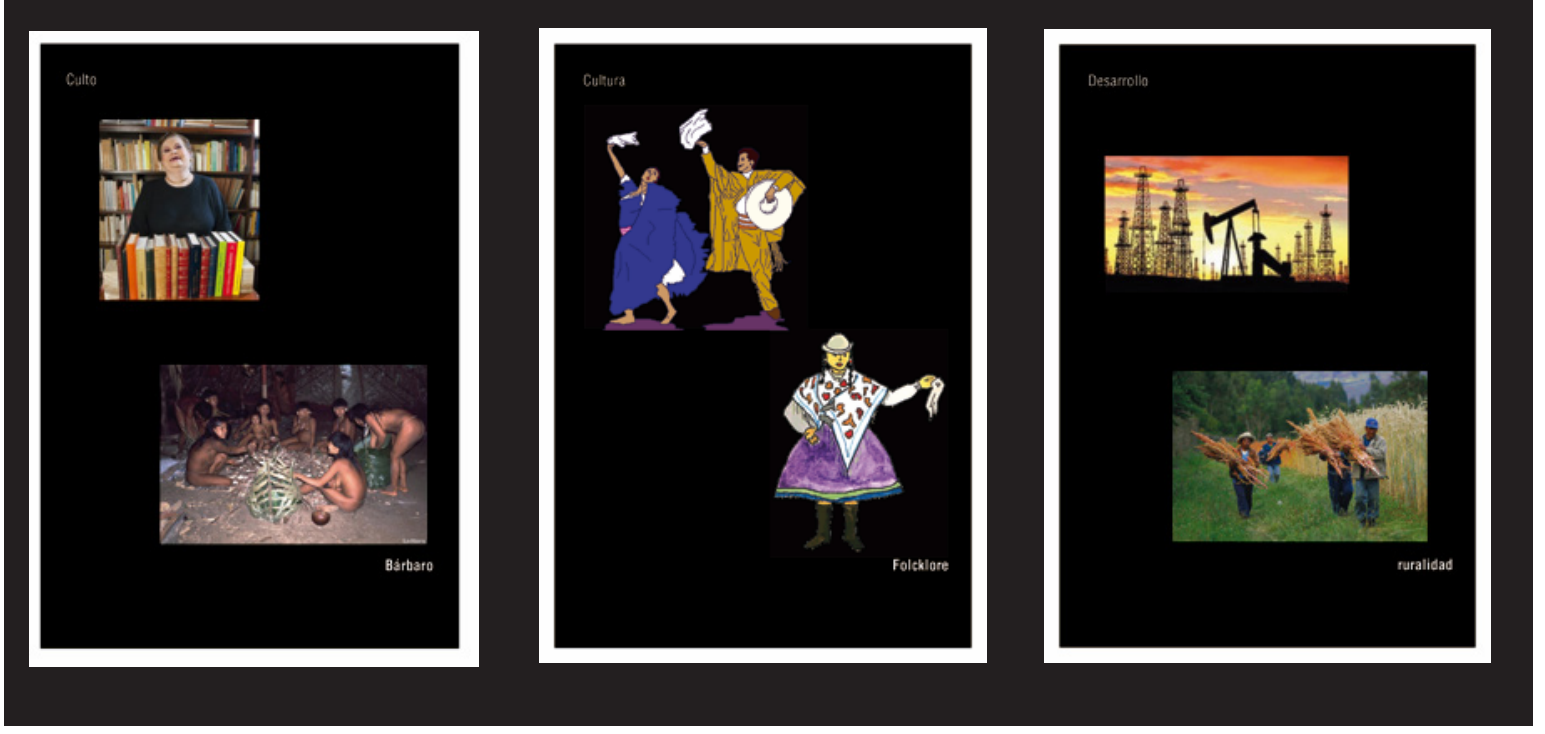

Fuente: "Repite conmigo. Didácticas del olvido" (Lima, 2016) para referirse a las estructuras narrativas utilizadas por Guamán Poma de Ayala.

En la Figura 14 se pueden observar dos (2) ilustraciones realizadas por asistentes al taller de crítica gráfica. La primera, al lado izquierdo, pertenece a David Orlando y se titula "¿El único Dios?"; al lado derecho tenemos "Estafó con By Pass", de Omar Allca. David Orlando presenta el tema central en forma de pregunta: ¿El único Dios? usando la dicotomía religión - creencia. En ella discute lavalidezy coherencia de la imposición religiosa a través 
de los personajes. La imagen de Jesucristo, en su función pedagógica y catequizadora, es puesta en cuestionamiento a través de dos (2) carteles contradictorios entre sí, sostenidos por un cardenal: "Censura" y "cuerpos desnudos y sexis permitidos en las iglesias".

Figura 14. Dicotomías expresadas en fanzine del Taller de Crítica gráfica.

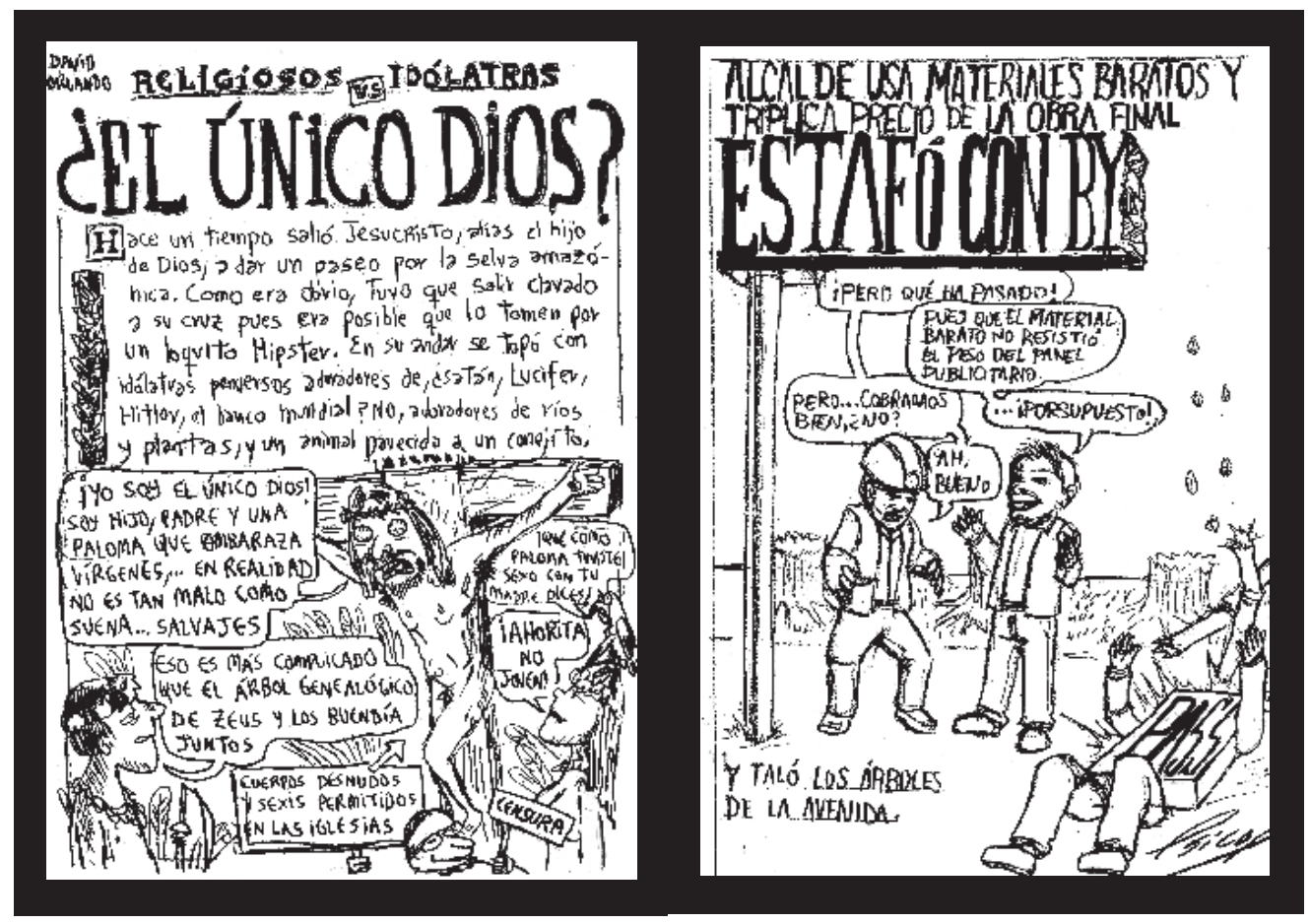

Fuente: Ana Carrasco, Juan Yáñez y Miguel Det. "El pensamiento dicotómico ilustrado", Lima, 2016.

Omar Allca aborda la paradoja desarrollo - atraso; toma como referencia la situación política de Lima. La fiebre desarrollista en esa ciudad tuvo su máxima expresión en la reelección del cuestionado alcalde Luis Castañeda; tuvo que responder por el sobrecosto de obras públicas que colapsaron ante fenómenos naturales por haber sido hechas con muy mala calidad de materiales. Otro de los grandes cuestionamientos realizado al alcalde durante ese periodo gubernamental fue el haber talado árboles en vías principales.

En esta quilca², Allca incorpora el paisaje, contexto y desarrollo de la situación narrada en el título, ubicado sobre una suerte de cartel de concreto resquebrajado del 
que se ha desprendido la palabra "pass" que, a su vez, yace sobre el cuerpo de una persona. En la zona inferior izquierda de la imagen puede leerse como subtítulo: "Y taló los árboles de la avenida". Los personajes centrales, el alcalde y un ingeniero, desarrollan el tema modular: la estafa. La composición descarta el uso de viñetas para resolverse en una sola imagen y utilizar globos de texto, título, subtítulo y personajes, como tiempos narrativos aleatorios.

Tanto David Orlando como Omar Allca son historietistas experimentados. Sin embargo, el uso de las quilcas les era ajeno. Varios de los demás asistentes, sin ser ilustradores, realizaron también discusiones dicotómicas muy bien resueltas en texto, imagen y símbolos. Se considera que las provocaciones puestas en los cuadernos de trabajo y la introducción a la quilca guamanponiana, de Miguel Det, permitió un desarrollo narrativo dinámico al prescindir de la linealidad. La narración aleatoria permite sostener toda la composición en torno a una situación central.

\section{Conclusiones y reflexiones sobre el proyecto “Repite conmigo. Didác- ticas del olvido"}

El pensamiento dicotómico como base estructural del proyecto "Repite conmigo. Didácticas del olvido" favorece el diseño de varias interacciones. Como resultado, ha develado estrategias del pensamiento dicotómico, como el encubrimiento y la negación. También funciona como filtro aplicable a la lectura crítica del contenido político de imágenes, enunciados, y demás, alusivos a la cultura e historia peruana.

A la hora de reflexionar sobre los resultados del proyecto, en espacios como la Facultad de Educación en la Universidad Sedes Sapientiae (2017) y la Facultad de Arte en la Universidad Central del Ecuador (2019), surge la discusión (desde la memoria y la percepción personal de los estudiantes) que América se resume en recursos; además, nuestra tarea, históricamente legitimada, es la del extraccionismo. Es decir, la ilusión modernista siempre ha sido dibujada desde las negaciones más que desde las posibilidades.

Por otro lado, el "Taller de crítica gráfica" reta a encontrar una herramienta decolonial en la estructura de la imagen, a la vez que creativa y posibilitadora de la reflexión

2 La quilca es la unidad narrativa que usa Guaman Poma de Ayala para narrar un hecho o acción. En el "Taller de Crítica Gráfica" (2016), Miguel Det usa el término de quilcas, cuando la estructura narrativa está inspirada en la obra Nueva Crónica y Buen Gobierno de Guamán Poma de Ayala y viñetas, cuando se usa el lenguaje de la historieta gráfica. 
crítica. Tomar como referencia la obra de Guamán Poma de Ayala es una invitación a investigar representaciones gráfico discursivas que contengan "valores andinos simbólicos" (Adorno, 1984, p. 67).

A partir de los elementos desarrollados en este proyecto, idealmente, la indagación posibilitará diseños más complejos de interacciones y herramientas con las que analizar, desde la crítica decolonial, el discurso político de imágenes y textos con los que se construyen las percepciones sobre cultura en sociedades coloniales.

\section{Referencias}

Adorno, R. (1984). Paradigmas perdidos: Guamán Poma examina la sociedad española colonial. Revista Chungará, 13, pp. 67-91.

Bustamante, F. (1999). La alteridad sus raíces y consecuencias. En Códigos de lo contemporáneo. Quito: Ediciones Abya Yala, pp. 136-137.

Carrasco, A., Det, M., y Yáñez, J. (2016). El pensamiento dicotómico ilustrado. Recuperado de: https://es.scribd.com/document/405108429/El-pensamiento-dicotomico-ilustrado

Det, M. (2011). Novísima crónica i mal gobierno. Lima : Editorial Contracultura.

Ensabap (2017) Memoria y ciudadanía. Recuperado en diciembre del 2019 de: https://lum.cultura.pe/cdi/documento/memoria-y-ciudadan\%C3\%ADa-recuento-del-programa-anual-de-exposiciones-2016

Fanon, F. (2009). Piel negra, máscaras blancas. Madrid: Ediciones Akal, S.A.

Figueroa, J. (2001). Del nacionalismo al exilio interior: el contraste de la experiencia modernista en Cataluña y los Andes americanos. Bogotá: Editorial Convenio Andrés Bello.

Glave, L. (2013). Entre la sumisión y la libertad, Sig/os XVII-XVIII. Lima: Editorial Derrama Magisterial. 
Hernández, M. (2000). ¿Es otro el rostro del Perú? Identidad, diversidad y cambio. Lima: Editorial AGENDA: Perú.

La República. (2016). Alan García. El error en Bagua fue extender el diálogo. Diario La República. Recuperado de: https://larepublica.pe/politica/734722-alangarcia-el-error-en-bagua-fue-extender-el-dialogo/

Marzal, M. (1993). Historia de la antropología indigenista: México y Perú. Barcelona: editorial Antrophos.

Madonado - Torres, N. (2012). Transdisciplinariedad y decolonialidad. Quaderna. Rescatado de: http://quaderna.org/?p=418

Novoa, M. (2015) Bolognesi. Lima, Ministerio de defensa.

Portocarrero, G. (2013) La utopía del blanqueamiento y la lucha por el mestizaje. Recuperado de: http://biblioteca.clacso.org.ar/clacso/gt/20130722095432/ Gonzalo_Portocarrero.pdf

Quijano, A. (2014). Colonialidad del poder, eurocentrismo y América Latina. Buenos Aires: Editorial CLACSO. Recuperado de: http://biblioteca.clacso.edu.ar/ clacso/se/20140507042402/eje3-8.pdf"

Trapnell, L. y Zavala, V. (2013). Dilemas educativos ante la diversidad, Siglos XX - XXI. Lima: Editorial Derrama Magisterial.

Victorio, E. (2014). El Perú llustrado y los héroes de la Guerra del Pacífico. Escritura y pensamiento. Año XVII, (35), pp. 59-76.

Vilca, E. (2009) "La imagen femenina: una visión contradictoria en el discurso del sujeto ilustrado en El Correo del Perú (1872)" en "La república de papel. Política e imaginación social en la prensa peruana del siglo XIX". Lima: Fondo Editorial de la Universidad de Ciencias y Humanidades. 